only with "Tristram Shandy," as being ever true to nature, will make them always live. The man himself has ever been the subject of love and affection. The words of the Laureate might well apply to him :-

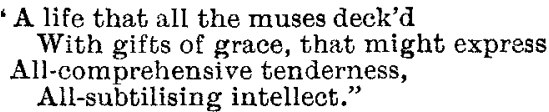

\section{CALCULUS IN A CHILD, REMOVED BY SUPRA-PUBIC CYSTOTOMY, FOLLOWED} BY PRIMARY UNION.

BY ROBERT WILLIAM PARKER, SURGEON TO THE EAST LONDOY HOSPITAT FOR CHILDREN.

THE following case seems worthy of record at a time when supra-pubic cystotomy is again on its trial. The little patient first came under my observation at the hospital in February last : he was then suffering from severe whoopingcough. Although his stone symptoms were very marked and sometimes painful, I thought it wise, nevertheless, to postpone the operation until the cough was better. In part perhaps owing to the long cold winter, little or no improvement in the cough took place until towards May; then it began to diminish, and on June 1st he was admitted. At this time he was a small, rickety, undergrown, anæmic child, just under three years of age, and could hardly walk. He was a native of the neighbourhood. For ten months past he had been noticed to pull at the prepuce a good deal; for seven months there had been increased frequency in micturition, with some straining during the act, but never any sudden arrest in the flow. The urine was said to get "thick on standing, to be often offensive, and never to have contained any blood." After his admission the urine was found to have a neutral reaction, and on standing threw down a considerable sediment of urate of ammonium. There was no albumen, and the urine was not offensive.

On June 4th, the usual preliminary enemata having been previnusly carried out, I performed supra-pubic cystotomy. The rectum was inflated with an indiarubber bag, the bladder distended with a warm solution of boric acid and retained by an elastic ligature placed round the root of the penis. The bladder was quickly reached and exposed through a median incision; a curved needle was passed through its coats on each side of the median line armed with silk, which was then used to raise and steady the bladder, and in some measure to retract the orifice of the incision which was now made into it with a small scalpel. The stone was quickly withdrawn by means of a small lithotomy forceps. $\Lambda$ fter this, the cavity of the bladder was explored with the finger to make sure that it was empty. A catheter was passed through the urethra, and a quantity of warm boracic solution injected in order to wash out any blood-clots and for the purpose of thoroughly purifying the wound. My next care was to carefully close the incision into the bladder : this I did by several sutures of fine chromic gut, after which the silk threads (temporarily put in to hold and steady the bladder) were withdrawn. The bladder now gradually contracted; the edges of the rectus muscles were brought together, and finally those of the incision through the external abdominal wall. A sprinkling of fine iodoform was applied to complete the antiseptic precautions; over this a pad of lint and a quantity of corrosive absorbent wool were fastened on with a flannel handage. He was given tincture of opium and kept very quiet for some hours after the operation. The dressing, having remained quite dry, was not changed for forty-eight hours. He had passed urine per urethram in natural quantity without effort or pain. On the fourth day after operation, the dressing was again changed. The wound being apparently healed, the external sutures were removed, and a broad band of fenestrated strapping was applied. The urine was of neutral reaction, and did not contain any albumen. The temperature remained normal throughout; the union gradually became firmer, was fully cicatrised in a fortnight, and the boy discharged well on June 20th, sixteen days after the operation.

I report this case of primary union after supra-pubic cystotomy, though it is a solitary case-I might almost say a unique one,-as a sample of what is possible, and what therefore we should endeavour to strive after; while I feel nevertheless, that this standard is rather too high a one for the generality of cases. In a former case, operated upon iwo or three months ago, 1 carefully closed the external incisions, putting a soft catheter through the urethra into the bladder with the intention of keeping the bladder quite empty and contracted, in the hope that thus the wound into its walls would close spontaneously. But I was disappointed; the vesical wound did not close, as urine began to dribble through it within a few hours. Besides this, the temperature rose to $102^{\circ} \mathrm{F}$., and remained higb, and the boy was very restless and uncomfortable. I attributed all this to the presence of the catheter, their disappearance on its withdrawal confirming this view. The case subsequently did very well; the incisions healed by granulation, but upwards of a month elapsed before they were quite repaired.

It appears to me, in the light of these cases, that when the tissues are healthy, as in these young subjects, an attempt to secure primary union should be made by carefully suturing the bladder, by a judicious use of sedatives, and by abstaining from all interference with the urethra. A catheter in the urethra causes as much irritation in a child as in an adult (a fact I had not sufficiently considered in my first case), and brings about those conditions, fever and restlessness, which are almost incompatible with primary union. Moreover, the mechanism of micturition seems to be interfered with. The boy, in whose case I left a catheter in the urethra, did not pass any urine per urethram for many days after the catheter had been finally discarded. Whereas in the case now under notice, thanks to the closed bladder and the absence of irritation, urine was voided normally from the first.

It may be asked why I discarded the old-established operation in favour of a new one, still on its trial. I can only reply that, in my judgment, the new operation has very much in its favour to recommend its general adoption : the high operation can be performed without danger to any important structures, whereas lateral lithotomy, even when done with anatomical accuracy, is a "leap in the dark," and cannot be performed without cutting in the close proximity of very important physiological structures one or other of which may possibly be wounded. I am not aware that primary union after lateral lithotomy has ever occurred, even by chance. If this case of mine proves to be a solitary one, it nevertheless shows what is possible after supra-pubic cystotomy. I was ably assisted at the operation by the resident medical officer, Mr. Battams; and $1 \mathrm{am}$ indebted also to Dr. Richards, resident clinical assistant, for anæsthetising the patient and for his careful record of the case. Old Cavendish-street, $\mathrm{W}$.

\section{A CASE OF}

TRAUMATIC STRICTURE OF THE URETHRA, TREATED BY INTERNAL URETHROTOMY AND CONTINUOUS DILATATION.

BY C. YELVERTON PEARSON, M.D., F.R.C.S.E., PROFESSOR OF MATERTA MEDICA IY QUEEN'S COLLEGE, CORK ; ASSISTANTSURGEON TO THE NORTH CHARYTABLE INFIRMARY AND CITY OF CORK HOSPITAL, ETC.

OwING to the few cases recorded in which the operation of internal urethrotomy has been undertaken for the relief of traumatic stricture, and the remarkably successful result which followed its performance under what I think may be regarded as rather unfavourable circumstances, I am induced to believe that the following case is one which will be read with attention by those who take an interest in urethral surgery.

C. T-, aged twenty-six, boiler-maker, presented himself on Aug. 17th, 1885, at the out-patient department of the North Charitable Infirmary. On the afternoon of the previous day he had fallen from a plank a distance of over four feet and came astride an iron bar. Immediately after the injury blood flowed freely from the urethra, and continued to do so for some time afterwards; he also passed very bloody urine each time be micturated. On examining the perineum, it was found to be slightly ecchymosed, as was also the back portion of the scrotum. There was no tume- 
faction or other evidence of urinary extravasation. Since the accident occurred there had been no difficulty in passing urine, but the act of micturition was attended with considerable pain, and was both preceded and followed by urethral hæmorrhage. I arrived at the conclusion that the patient was suffering from partial laceration of the urethra. I ordered him to be immediately admitted into hospital, and (as the surgeon for the day had left) gave instructions for him to have a warm bath, and a draught containing twenty minims of sedative solution of opium and ten minims of tincture of belladonna, to be repeated every six hours; also, in case retention occurred, to have a No. 10 gum-elastic catheter (with stilet) passed, and tied in.

On arriving at the hospital the following morning, the clinical clerk informed me that on the previous evening, owing to retention, the instrument had been passed, but was removed when the bladder had been emptied; its use had not been attended with any difficulty or hæmorrhage, and the patient, finding himself subsequently able to pass urine free from blood, had (much to my astonishment) left the hospital early that morning. I naturally anticipated that he would reappear on some future occasion. In this I was not mistaken, as he came to my house on Sept 22nd, complaining of great difficulty in passing urine, and said there was much diminution in the size of the stream, which conditions were becoming rapidly more marked during the past week. On endeavouring to pass a No. 6 English gum-elastic instrument, it was abruptly arrested at the bulbous portion of the urethra. I now tried various instruments of smaller size, and ultimately succeeded in passing a No. 4 French bougie (about No. 1 English), and this was tightly grasped. I now informed the patient that his condition required prompt and careful treatment, and strongly urged him to go into hospital and submit to an operation; this he refused to do, as he said he was engaged at some special work, which he would lose if he did not return to it immediately; he, however, promised to come to me twice a week to have instruments passed, but could not do so more frequently, owing to his business being at a considerable distance. He continued to attend for a few weeks, and I succeeded in increasing the calibre of the stricture to No. 7 French (between 2 and 3 English), but could not get beyond this. I also noticed that the instrument passed with great difficulty through the membranous portion of the urethra. He now said that he had much inconvenience in attending, but could continue to do so once a week. I told him that I did not think the occasional passage of instruments would improve his condition any further, and that he must ultimately submit to an operation. I also gave him Nos. 5 and 6 French bougies, which I instructed him how to pass for himself every other day. He continued this mode of treatment up to the middle of November, when, owing to his contract being fulfilled, he "went on the spree," and came to me on the evening of Nov. 26th, suffering from retention, great pain, and an overdistended bladder. I endeavoured to pass an instrument of the smallest size, but was unable to do so. I then gave him a note to the house-surgeon of the North Infirmary, ordering a warm bath and full opiate, and saying that, if he failed in relieving him, I should be sent for. The house-surgeon, not finding the above measures succeed, tried to pass a fine catheter, but could not do so, and, not wishing to disturb me at such a late hour, tried a second bath; this proved successful, but the patient, finding himself able to pass urine in the morning, left the hospital. He again took drink and reappeared in the afternoon suffering from retention, when he had a warm bath, and while in it a fine catheter was passed and tied in ; the patient, however, removed it himself in the morning and again left the hospital. He came to my study in the afternoon and inquired into the nature of the operation that I bad recommended. I strongly urged him to have Syme's operation performed, but he strongly objected to any such severe measure. I then explained to him that an internal operation might be done, but I could not guarantee such a successful result as I anticipated from the former. He consented to submit to internal urethrotomy, but disliked so much remaining in hospital that I undertook to perform it at his own home. Being anxious, if possible, to divide the stricture from behind forwards, I determined to first try continuous dilatation for a few days. On Nov. 30th I accordingly tied in a No. 3 French catheter, which was the largest I could pass. As the urine did not flow freely enough through this, the patient had to remove it during the night. On the following day I passed a No. 1 English gum-elastic; on Dec. 2nd I changed this for a No. 3 ; on Dec. 3rd I got in a No. 5 , and promised to operate the following day, as the subject of $\mathrm{my}$ treatment was getting highly impatient at the delay.

Operation.-On the morning of Dec. 4 th, the patient being fully under the influence of chloroform, I first tried to pass a No. 6 catheter, but could not, showing that the No. 5 had effected little or no dilatation since the previous day. I then introduced Sir H. Thompson's modification of Civiale's urethrotome, and passed it through a short stricture situated in the anterior part of the bulb, but was unable to get it through a second one, commencing probably at the junction of the membranous with the bulbous urethra. On withdrawing the instrument one-third of an inch, it was arrested by the anterior stricture; this I freely divided from behind forwards. I now introduced the staff of a Teevan's urethrotome, and then, as urine appeared from the groove, passed down the concealed blade to the seat of stricture. This I attempted to divide, but at first failed to do so, the stricture apparently being pushed backwards by the instrument, notwithstanding that the penis was kept on the stretch. I then directed my assistant to extend it still more forcibly, and after another trial succeeded, though great force had to be employed, the stricture cutting like cartilage. On withdrawing the instrument there was a moderate amount of hæmorrhage, which soon ceased. Finding the meatus congenitally contracted, I incised it, and then tried to pass a large curved metalic sound, but failed to get it through the membranous portion. 1 again introduced Thompson's urethrotome, and this time it passed readily through the second stricture, which I now divided on the floor from behind forwards. 1 again attempted to pass the large metallic sound, but could not do so. I also failed to pass a large-sized elastic catheter. Not having intermediate instruments at hand, I introduced a No. 6 English gum-elastic catheter, and tied it in. A half-grain morphia suppository being placed in the rectum, the patient was put to bed, and ordered a draught containing fifteen minims of sedative solution of opium, to be given in six hours after, and to be repeated every sixth hour if necessary.

The following day (Dec. 5th), finding the patient in a most satisfactory condition, able to urinate easily through the catheter, and that no urine flowed by the side of it, I determined to leave it undisturbed.-Dec. 6th: Withdrew the No. 6, and introduced a No. 8 , without encountering the slightest difficulty or obstruction.-7th: Removed the No. 8, and passed a No. 10 with great ease.-9th : Remored the No. 10, and passed a No. 12 quite easily.-11th: Removed the No. 12 catheter. I now passed in succession three conical metallic sounds, Nos. 14, 15, and 17, English size; these all passed quite readily, and with neither of them was the 'slightest obstruction felt at the seat of stricture; No. 17 was, however, a tight fit at the meatus. The patient was now left, for the first time since the operation, without a catheter, and was permitted to get up the following day the metallic sounds being again passed; these were also used for the next few days. He was then provided with Nos. 23 and 25 French gum-silk bougies, which he was instructed to pass daily for a time, then on alternate days, and gradually to increase the interval to two or three days; he was also strongly warned of the evil of the intemperate habits to which he had been previously addicted. I should mention that the progress of the case was not attended with any constitutional disturbance, the temperature never having risen above $99^{\circ} \mathrm{F}$

Subsequent history.-The patient came to me a few times during the few weeks following the operation to report favourable progress, but was not again seen by me since the end of last December until the eve of writing this paper-viz., March 23rd, 1886, - when he came at my request, so that I might ascertain his condition. He then informed me that he had continued to pass the instrument at intervals varying from two to four days, that he had not experienced the slightest difficulty in micturition, although he had on several occasions partaken very freely of stimulants. I passed a No. 23 French bougie without difficulty, though it was slightly grasped during withdrawal. I also passed a No. 20 metallic bulbous exploring instrument, with which I was able to detect the previous sites of both the strictures. I made no further examination.

Observations.-I have described the foregoing case, not with the object of advocating the operation of internal urethrotomy in cases of traumatic stricture, but rather as an illustration of the amount of good that may be derived 
from it, and also because it has been so rarely undertaken in such cases. Although I am pretty extensively acquainted with the literature of urethral surgery, I can only at this moment recall a single recorded instance where internal urethrotomy has been performed for traumatic stricture. This case was one related by Mr. Teevan and reported in the Proceedings of the Clinical Society of London, in which both an old-standing traumatic stricture and several penile tistulæ were cured by the operation. In the case I have related, had I the option of choosing, I should have preferred performing either Syme's operation or a combunation of internal and external urethrotomy, such as advocated for some cases of stricture by Dr. Otis, and also by Mr. Reginald Harrison. It may be asked wl!y I did not at once after the operation succeed in introducing a large instrument. To this I can only answer by offering the explanation which presented itself to $\mathrm{my}$ mind at the time-viz., that although I had divided the stricture, the cicatricial ring still remained in such an unexpanded condition that it would not admit the end of a large instrument, just as would occur with a metallic ring when cut at one place. Having formed this opinion, I determined to carry on the process of continuous dilatation, and nsert between the divided ends what has been aptly termed by Gouley "a cicatricial splice," as a jeweller would enlarge a finger-ring by the introduction of a new piece of metal, the object in both cases being to permanently enlarge the diameter of the circle. In conclusion, I may point out that the patient's habits, inclinations, and dislike to remaining in bed were serious obstacles to the course of treatment; and, on the whole, it is rather surprising that such a successful result has been attained.

P.S.-At the time of correcting the proof of this paperviz., June 29 th, $1886-1$ find upon inquiry that the patient continues in the same satisfactory condition as when last examined by me.

\section{OBSERVATIONS WITH REFERENCE TO THE THEORY OF THE RESPIRATORY MUURUR,}

AND THE SEAT OF ORIGIN OF THE SO-CALLED VESTCULAR MURMUR, IN A CASE IN WHICH THE LARYNX WAS EXTIRPATED BY DR. NEWMAN.

\section{BY JOSEPH COATS, M.D.}

BY the kindness of Dr. Newman 1 have had the opportunity of making some observations on a patient of his, chiefly in regard to the origin and propagation of the laryngeal and pulmonary auscultatory phenomena. In the first place it may be well to state the points which these observations were intended to bear on.

A very excellent summary of the principal facts bearing on the causation and mode of production of cardiac and respiratory murmurs is given by Hilton Fagge, first in an article in the Medico-Chirurgical Review for July, 1873, and again in his book on "Practice of Medicine," recently published. It is now generally believed that the various cardiac and vascular murmurs are produced by what is technically called a veine fluide. When a jet of fluid, whether liquid or gas, issues from a narrow space into a wide one, a blowing sound is produced, the form which the fluid takes under such circumstances constituting the veine fuide. So far as the larynx and trachea are concerned, the conditions for a blowing sound are fulfilled at the glottis, where, both in inspiration and expiration, the air issues from a narrow aperture into a wider space. We have accordingly at the glottis a loud blowing sound both with inspiration and expiration. In regard to the more remote parts of the respiratory tract, there is only one place where the due conditions are present, according to the theory, for the production of a veine fuide, and that is where each minute bronchiole opens into the somewhat wider infundibulum or group of air vesicles. During inspiration the air passes here from a narrower tube into a somewhat wider

1 This paper was read at the Pathological and Clinical Society on May 1Ith, 1886, and as the observations seemed to be of importance in relation to the origin of the respiratory murmurs, a committee was appointed to go over the points with me, and to report. The committee consisted of Professor Gairdner, Dr. Newman, Dr. J. Lindsay Steven space, but during expiration it does not do so. The obvious conclusion that the normal respiratory murmur, which is essentially a sound of inspiration, has origin in a veine Auide occurring in the multitudinous infundibula, has not remained unchallenged. It has even been asserted that the sound does not originate in the lung at all, but is propagated from the larynx. This view seems to have been first asserted by M. Beau, and since his day the controversy has ranged around that point, with a general result unfavourable to his views. It seems to be a law of the veine fuide that the sound produced is most easily propagated in the direction in which the fluid is moving. According to this law, the expiratory glottic sound should not be audible over the trachea, whereas, as a matter of fact, it is usually louder than the inspiratory. Bergeon explains this on the ground that the false cords and the base of the epiglottis form a kind of lip or rim, under which circumstances, as experiment has shown, the sound may be projected backwards against the current, just as a regurgitant aortic murmur is propagated against the current, and is audible over the aorta. It will appear from our observations that this explanation hardly holds.

Turning now to these observations, I may describe briefly the local conditions. The larynx had been removed, and in its place there was a tube formed of vulcanite. This tube is about half an inch in diameter, being nearly that of the trachea, and it forms, in fact, a direct continuation upwards of the trachea, its lower orifice being embedded in the mucous membrane, so that there is no sudden alteration of calibre. The tube fixed in the upper end of the trachea is bent forward and emerges from the wound in the neck with an open mouth, retaining its full diameter throughout. By this means the trachea is continued outwards without the interposition of the larynx or the parts above it, and continued virtually in its full calibre. From the upper side of this tube a shorter and narrower one proceeds into the pharynx, and the patient can breathe through this tube when the large outer one is closed. This smaller tube I shall call the pharyngeal tube, the larger being the tracheal. By slight alterations in this apparatus I was able to obtain three different conditions, and to study the changes in the auscultatory phenomena produced thereby. These were(1) The tracheal tube wide open with the pharyngeal tube open or closed, so that breathing was carried on essentially by the wide tracheal tube; (2) the tracheal tube closed and the pharyngeal one open, so that breathing was carried on through the narrow pharyngeal tube; (3) the tracheal tube partially closed by a stopper, through which was passed a much narrower tube, so that breathing was carried on through this narrower tube.

1. The tracheal tube open, and breathing carried on through it-a condition equivalent to the elimination of the larynx and buccal cavity. In Hilton Fagge's paper already alluded to experiments are referred to by Bergeon and Boudet in which the trachea of a horse was cut across and drawn forward out of the body, so as to eliminate the larynx, as in our observations. They assert that as a result the glottic murmurs disappeared entirely, this being quite consistent with the view that they originate in veines fuides at the glottis. My observation scarcely agrees with this, however. A loud expiratory blowing sound was produced at the external orifice of the tube, so loud as to be audible at some distance from the patient. There was here obviously the precise condition for the development of the veine fluidenamely, a tube opening into a wide space, the sound being similar to that produced when we form with the lips a round aperture and blow through it, and having obviously a similar mode of origin. This loud expiratory sound was propagated down the trachea and apparently to the larger bronchi. Auscultation in the supra-sternal notch and directly over the trachea revealed a loud blowing expiratory sound and a very feeble inspiratory one. The results of auscultation over the root of the lung behind were very interesting. It was found that the difference in intensity between the expiratory and inspiratory sounds had become much less, so that the conditions resembled those of ordinary bronchial breathing, the expiratory being as loud or almost as loud as the inspiratory sound. There was, however, a marked difference in quality in the two sounds, the expiratory retaining the blowing tubular character, while the inspiratory partook rather of the quality of the vesicular murmur. It may be inferred, I think, that the equalisation of the two sounds as regards intensity was largely due to the inspiratory becoming reinforced by the normal vesicular murmur, and 